\title{
Finite element analysis of advanced bicycle precision brake disk forming technology
}

\author{
Dyi-Cheng Chen ${ }^{a}$, Jing-Hao Kang, and Chia-Chun Lai \\ Department of Industrial Education and Technology, National Changhua University of Education, \\ Changhua 500, Taiwan
}

\begin{abstract}
In recent years, the bicycle has become an environmentally friendly transportation. The bicycle can be divided into mountain bicycle and highway bicycle. Safe driving is the prior consideration. The bicycle braking system can be divided into oil pressure disk brakes and mechanical disk brakes. The brake disk system is one indispensable component of the safe system. In accordance to overall weight consideration of the bike, the brake disk should also focus on the lightweight design. This paper discussed an innovative brake disk forming technology for 6061 aluminum alloy by the rigid-plastic finite element analysis. The simulation parameters include geometric shapes of the brake disk and mold, die temperature, and friction factors. The stress and strain in forming, brake deformation and vibration modal analysis of brake disk in riding were studied. The paper is expected to offer some precision bicycle brake disk manufacture knowledge for industry.
\end{abstract}

\section{Introduction}

Bike riding safety goal for us to consider, when the bicycle brake calipers lived through the brake disc brake disc wallet braking force so that the tire stops the process is the use of the friction brake to stop rotation of the tire. It will generate heat friction, dish the reason why there are many holes in the disk evil. Because they can help dissipate heat, so you can prevent overheating of the brake system to generate heat exhaustion phenomenon. Because the downhill braking deceleration tend to use, but it will slow down at the same time produces steel disc brake calliper, disc friction, disc brake, disc temperature will increase at this time. In order to overcome this problem will change for the aluminum disc brake disc. Moreover the 6061 aluminum alloys have a lighter quantization, easily recovered with high strength, high corrosion resistance, high formability and non-toxicity property.

Metal forming industry, stamping can reduce production time to improve the competitive market, so aluminum stamping is a very promising area of research, the technology used for cold pressing and hot pressing of the working conditions [1]. Naden et al. [2] considers that mentioned steel, semi-hot stamping process may be considered to improve the hot stamping method, which not only ensures high formability, but also increase the strength values. Santo et al. [3] used the finite element method to predict the behavior of materials, the estimated change in the shape and size of the finished product as

\footnotetext{
${ }^{\mathrm{a}}$ Corresponding author: dcchen@cc.ncue.edu.tw
}

This is an Open Access article distributed under the terms of the Creative Commons Attribution License 4.0, which permits unrestricted use, distribution, and reproduction in any medium, provided the original work is properly cited. 

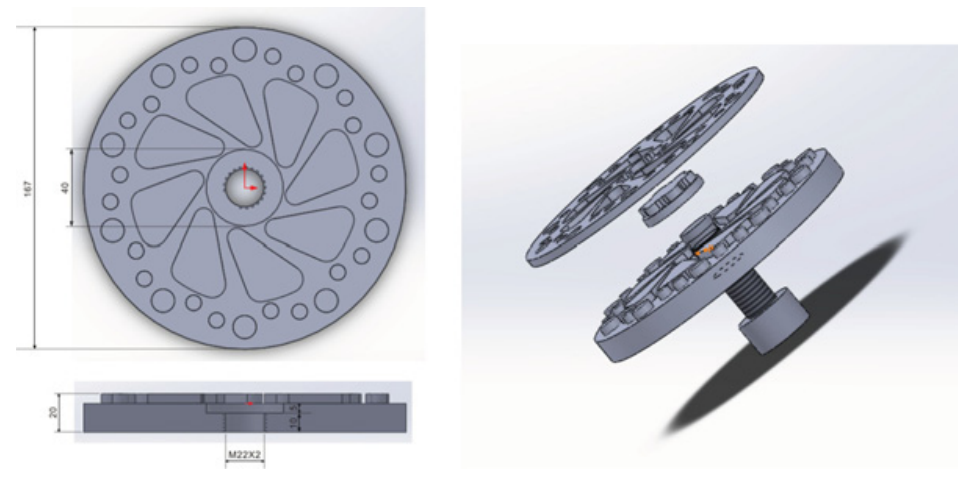

Figure 1. Brake disk die dimensions and exploded view.

well as the shape of the experimental results and the real defects that may exist as a consistent shape deformation. Ketabchi et al. [4] used finite element method to improve the accuracy of the touch panel forming draw bead element analysis. Behren et al. [5] depends on the structural components of the stress distribution for different materials in high strength and toughness properties. Nemat-Alla [6] used finite element method analysis for tapered necking die eccentric necking process.

Parvizian et al. [7] mentioned aluminum structure to be light weight, high strength, good thermal conductivity, easily processed of bicycle parts billet. Liu et al. [8] found finite element model that the shape effect on the overall fine blanking. Sapanathan et al. [9] found the thickness of the gap for shear bond strength test and blanking period at maximum strain. Achouri et al. [10] validated the simulation of this approach to the ability precise manner, damage evolution in the shearing process. Ghiotti et al. [11] found micro hardness testing and metallurgical observed shear plane for quality evaluation. [12]. Kim et al. [13] analyzed its mechanical plastic deformation behaviour, punching pressure and other process parameters.

In this study, rigid-plastic finite element analysis software DEFORM 3D for 6061 aluminum alloy and 7075 aluminum alloy brake disk for metal forming analysis, the main factors include brake disk thickness, brake disk geometry through analysis that the stress/strain bicycle brake disk after forming, and analysis software with ANSYS Workbench vibration modal analysis of brake disks.

\section{Brake disk design}

In the die design process to easily assemble, fast form removal based. Figure 1 shows brake disk die important dimensions and exploded view. It shows a schematic diagram including die wear calculation model, analysis of die wear. The analysis software DEFORM gives two computing model including Archrd model and Usui's model. Archrd model is based on the calculation of abrasive wear target, the main application in the metal forming die wear analysis. It is most classic wear model. Usui's model shows adhesive wear as the main computing objects, general used in metal cutting tool wear [12]. Archrd wear mode expressed as follows.

$$
Z_{A B}=\int K \frac{p^{a} v^{b}}{H^{c}} d t
$$

where $\mathrm{Z}_{\mathrm{AB}}$ is wear depth, $p$ is the interface pressure, $v$ is the slip velocity, $H$ is the hardness of the die and $t$ is time. 


\section{ICNFT 2015}
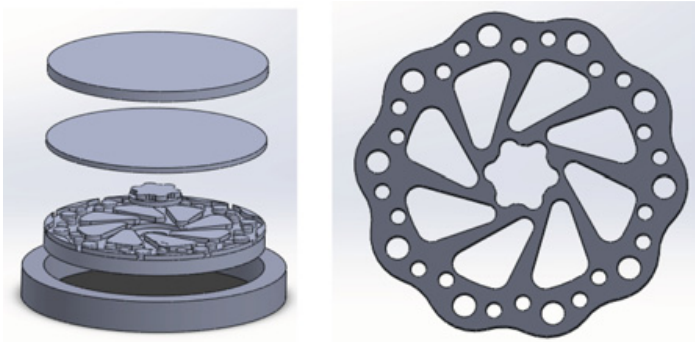

Figure 2. The first model exploded and brake disk prototype.
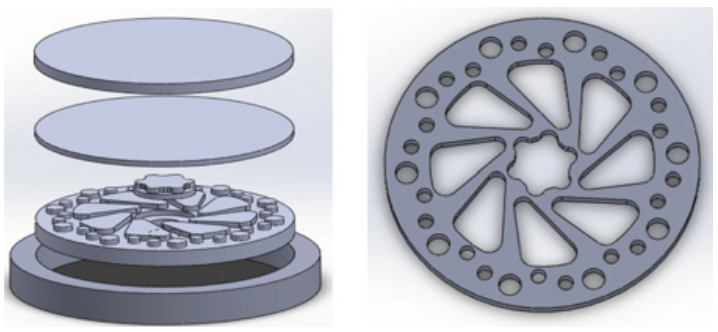

Figure 3. The second model exploded and brake disk prototype.
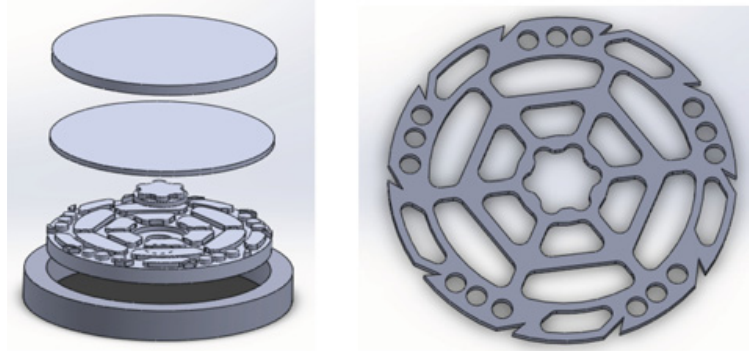

Figure 4. The third model exploded and brake disk prototype.

The brake disk design concepts from commercial steel brake disk geometry, using Solidworks software drafted the entire group of die. Figures 2, 3 and 4 show innovative design of three different bike brake disk to achieve a lightweight structure brake disk.

Stamping simulated bicycle brake disk for design parameters including punch speed, billet temperature, brake disk geometry shape, friction factor and die temperature. Figures 5, 6 and 7 show three different molding processes for bicycle brake disk stamping. It analysis should attention punch wear and billet rupture area, through complete experimental design and production planning, and with the expert advice and mold aspects of the exchange of views. Finally, the experiment should be noted the maximum pressure of machine and add an appropriate lubricant (such as molybdenum disulfide, graphite, etc.).

\section{Results and discussions}

The paper used rigid-plastic finite element analysis DEFORM ${ }^{\mathrm{TM}} 3 \mathrm{D}$ simulation software for the bicycle brake disk stamping, with brake disk thickness and brake disk geometry are an important process 


\section{MATEC Web of Conferences}

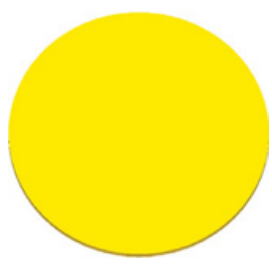

before forming

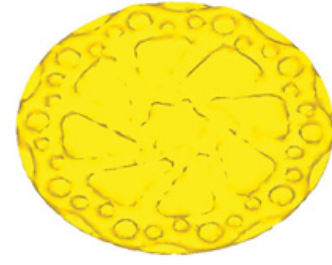

during forming

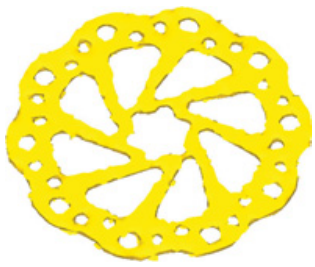

after forming

Figure 5. The first brake disk molding process diagram.

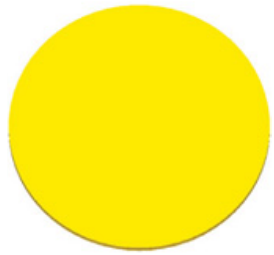

before forming

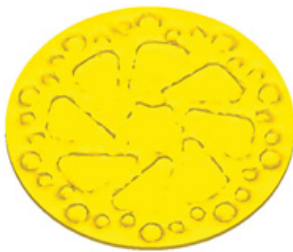

during forming

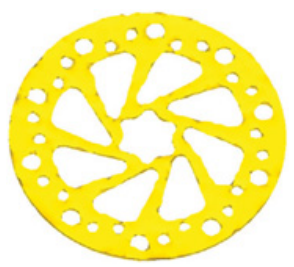

after forming

Figure 6. The second brake disk molding process diagram.

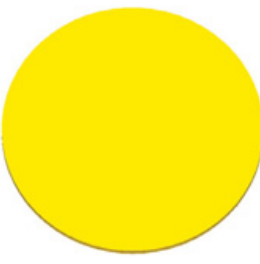

before forming

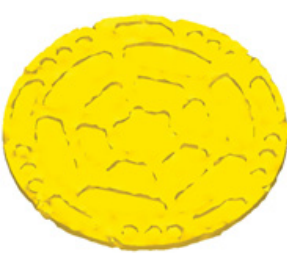

during forming

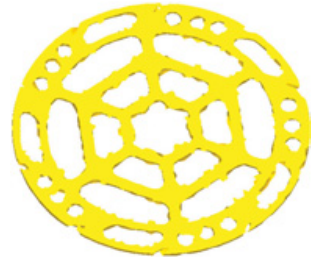

after forming

Figure 7. The third brake disk molding process diagram.
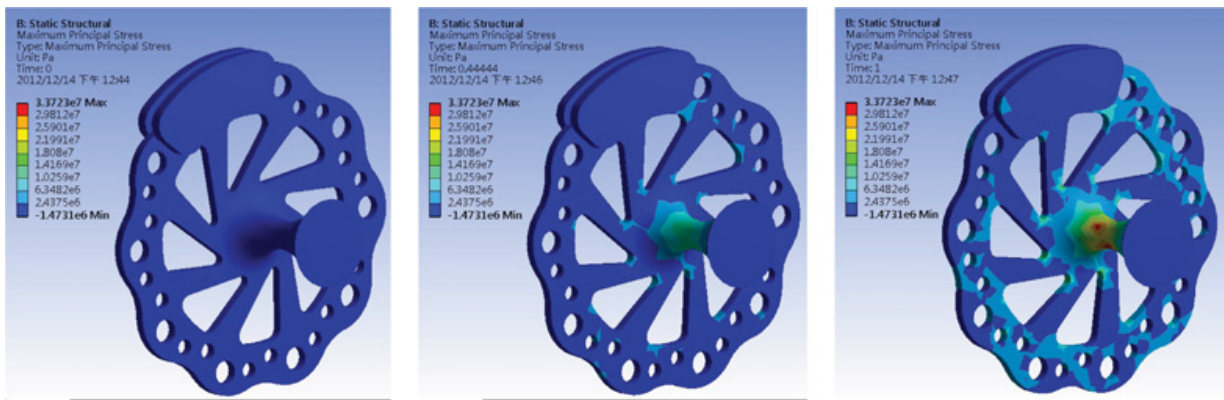

Figure 8. Bicycle brake disk stress modal analysis chart.

parameters, preliminary simulation bicycle brake disk and vibration modal analysis using ANSYS multiphysics coupling vibration modal analysis software. The simulation shows brakes when going downhill bike riding, brake stress, strain and deformation of whole brake disk. Figure 8 shows stress modal 
Table 1. Vibration modes of bicycle brake disk.

\begin{tabular}{|l|l|}
\hline Mode & Frequency [Hz] \\
\hline 1 & 0 \\
\hline 2 & $2.6311 \mathrm{e}-003$ \\
\hline 3 & $3.0271 \mathrm{e}-003$ \\
\hline 4 & $3.0778 \mathrm{e}-003$ \\
\hline 5 & $4.135 \mathrm{e}-003$ \\
\hline 6 & $4.5735 \mathrm{e}-003$ \\
\hline
\end{tabular}
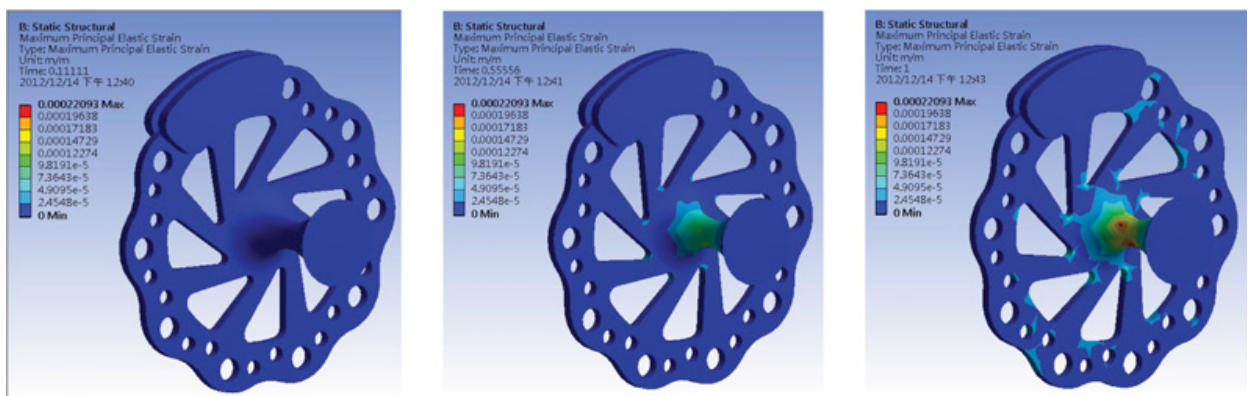

Figure 9. Bicycle brake disk stress and strain modal analysis chart.

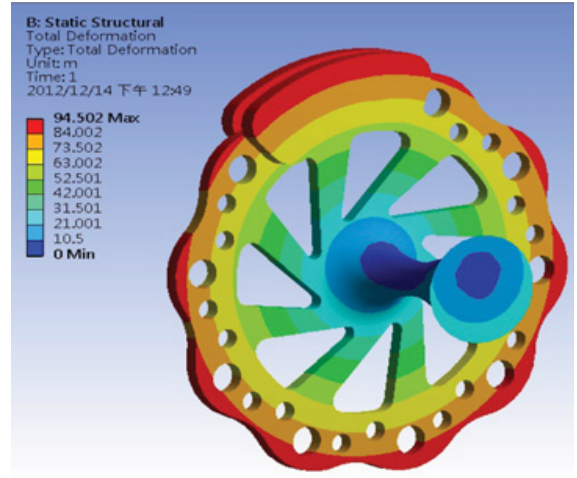

Figure 10. Total deformation of bicycle brake disk.

analysis chart of bicycle brake disk. Figure 9 shows brake strain modal analysis chart of bicycle brake disk.

In this study, using ANSYS multi-physics coupling analysis of vibration modal analysis software to simulate bike riding, bicycle brake disks in various modes of vibration frequency of the steady-state analysis and obtained total deformation of bike brake disk. Table 1 shows the maximum deformation in the outermost brake disk according to Fig. 10.

\section{Conclusions}

The bicycle industry is currently prosperous, and Taiwan's market mainly focuses on the production and development of high-price parts for various sectors. Riding bicycle is not only environmentally friendly and healthy, but also alleviates environmental pollution. The paper used the rigid-plastic finite element analysis software to study an innovative brake disk forming technology for 6061 aluminum alloy. 


\section{MATEC Web of Conferences}

The results indicate that: (1) the analysis should be focused on the punch wear and billet rupture area; and (2) the maximum deformation occurs in the outermost brake disk.

\section{References}

[1] M.P. Pereira, F.B. Rolfe, J. Mater. Process. Technol. 214, 1749 (2014)

[2] M. Naderi, M. Ketabchi, M. Abbasi, W. Bleak, J. Mater. Sci. Technol. 27, 369 (2011)

[3] A.D. Santos, J.F. Duarte, A. Reis, D.B. Rocha, R. Neto, R. Paiva, J. Mater. Process. Technol. 119, $152(2001)$

[4] M. Naderi, M. Ketabchi, M. Abbasi, W. Bleak, J. Mater. Sci. Technol. 27, 369 (2011)

[5] B.A. Behrens, A. Bouguecha, C.M. Gaebel, J. Moritz, J. Schrödter, Procedia Eng. 81, 1756 (2014)

[6] M. Nemat-Alla, J. Manuf. Sci. Eng. 130, 011006 (2008)

[7] F. Parvizian, T. Kayser, C. Hortig, B. Svendsen, J. Mater. Process. Technol. 209, 876 (2009)

[8] Y. Liu, H. Lin, H. Mao, W. Feng, Procedia Eng. 81, 1108 (2014)

[9] T. Sapanathan, R. Ibrahim, S. Khoddam, S.H. Zahiri, Mater. Sci. Eng. A, 623, 153 (2015)

[10] M. Achouri, G. Germain, D. S. Philippe, D. Saidane, Comput. Mater. Sci. 72, 62 (2013)

[11] A. Ghiotti, S. Bruschi, P. Regazzo, Procedia Eng. 81, 2512 (2014)

[12] DEFORMTM 3D Version 6.1(sp1) User's Manual (Scientific Forming Technologies Corporation, Columbus, 2006)

[13] P.H. Kim, M.S. Chun, J.J. Yi, Y.H. Moon, J. Mater. Process. Technol. 130-131, 516 (2002) 